\title{
Public Attitudes on Transgender Military Service: The Role of Gender
}

\author{
Daniel C. Lewis ${ }^{1}$ \\ Barry L. Tadlock ${ }^{2}$ \\ Andrew R. Flores ${ }^{3}$ \\ Donald P. Haider-Markel ${ }^{4}$ \\ Patrick R. Miller ${ }^{4}$ \\ Jami K. Taylor ${ }^{5}$
}

\begin{abstract}
Policy regarding the inclusion of transgender soldiers in the U.S. military has shifted back and forth in recent years, with public opinion likely a significant factor shaping the eventual policy outcome. As such, this study examines the factors that shape public attitudes toward military service by transgender people. In particular, we examine the influence of sex, social gender roles, and attitudes toward gender in shaping transgender military service attitudes. Further, we hypothesize that personal experiences with the military and with transgender people, along with values, personality predispositions, and religion, are likely to influence individual attitudes. We test these hypotheses using data from a unique October 2015 national survey of American adults. The results suggest that personal experiences, attitudes toward gender roles, and religion have substantial, but sometimes conditional effects on attitudes towards military service by transgender people.
\end{abstract}

\footnotetext{
${ }^{1}$ Siena College, Loudonville, NY, USA

${ }^{2}$ Ohio University, Athens, OH, USA

${ }^{3}$ American University, Washington, DC, USA

${ }^{4}$ University of Kansas, Lawrence, KS, USA

${ }^{5}$ University of Toledo, Toledo, $\mathrm{OH}$, USA
} 


\section{Author Biographies}

Daniel C. Lewis is an Associate Professor and Chair of the Department of Political Science \& International Relations at Siena College. His research examines policy representation in state politics. He is the author of Direct Democracy and Minority Rights and coauthor of The Remarkable Rise of Transgender Rights.

Barry L. Tadlock is an Associate Professor of Political Science at Ohio University. He is the coeditor (with Ellen D. B. Riggle) of Gays \& Lesbians in the Political Process (1999). His work on LGBT politics has appeared in Public Opinion Quarterly, Political Psychology, Politics, Groups, and Identities, and elsewhere.

Andrew R. Flores is an Assistant Professor of Political Science in the Department of Government at American University. His research focuses on attitude formation and change about marginalized groups, particularly the LGBT community.

Donald P. Haider-Markel is a Professor and Chair of Political Science at the University of Kansas. His research and teaching is focused on the representation of interests in the policy process and the dynamics between public opinion, political behavior, and public policy.

Patrick R. Miller is an Associate Professor of Political Science at the University of Kansas. His research examines public opinion, political psychology, and elections.

Jami K. Taylor is a Professor of Political Science and Public Administration at the University of Toledo. With Daniel Lewis and Donald Haider-Markel, she is an author of The Remarkable Rise of Transgender Rights (2018, University of Michigan Press).

\section{Funding}

This study was funded by the University of Toledo, University of Kansas, the Williams Institute at the UCLA School of Law, and Ohio University.

\section{Corresponding Author}

Daniel C. Lewis

Department of Political Science \& International Relations

Siena College

515 Loudon Rd.

Loudonville, NY 12211

(518) 782-6652

dlewis@ siena.edu 
For more than 25 years, the U.S. has experienced political and cultural upheaval at the intersection of LGBTQ populations, gender, and military issues. From 1993 to 2011, the Don't Ask, Don't Tell (DADT) policy barred openly gay, lesbian, or bisexual individuals from serving in the military, but it was silent on whether transgender people could serve. They were, however, excluded by military medical standards and other regulations. During this same period, the visibility of transgender issues increased along with that of the broader LGBTQ community. Indeed, when President Obama repealed DADT in 2011, transgender rights had already become an important component of the LGBTQ rights movement (Taylor \& Lewis, 2014). Yet, the repeal of DADT did not actually allow transgender people to serve in the military. In 2014, Defense Secretary Chuck Hagel asserted that the military should review its prohibition on transgender people. Just two years later, Defense Secretary Ash Carter announced that “transgender Americans" could serve openly (Bromwich, 2017), which coincided with the decision to allow women to serve in military combat units. The decision on transgender service followed the example of Canada, which lifted its ban in 1992 and adopted explicitly inclusive policies in 2010 and 2012 with no loss in operational effectiveness (Okros \& Scott, 2015). ${ }^{1}$

More recently, the Trump administration reinstituted a near total ban on transgender people serving in the military. Transgender people were barred from service if they had transitioned, were transitioning, or otherwise engaged in activities that allowed them to lead their lives according to their gender identity (Sonne \& Marimow, 2019). The stated rationale for a ban was “"tremendous medical costs and disruption” of allowing such troops to serve" (The Economist, 2018). The Palm Center, an independent institute focusing on LGBTQ issues in the military, contends the ban echoes DADT in that "transgender troops will be forced to leave the military or to serve in silence" (Palm Center, 2018, p. 1). In less than four years, openly 
transgender military personnel went from being banned from service, to being allowed to openly serve, and back to being banned once again (Taylor, Lewis, \& Haider-Markel, 2018).

These policy shifts are not just political fodder. Estimates derived from the National Transgender Discrimination Survey (NTDS), one of the largest surveys of Americans who identify as transgender or gender non-conforming, ${ }^{2}$ show that these policies affect a substantial number of military service members: “[a]pproximately 15,500 transgender individuals are serving on active duty or in the Guard or Reserve forces ... and there are another 134,300 transgender individuals who are veterans or are retired from Guard or Reserve service" (Gates \& Herman, 2014, p. 1). In fact, transgender Americans are twice as likely to have served in the military as the general population (Gates \& Herman, 2014). While it seems paradoxical that transgender people serve at such high rates, gender-dysphoric individuals born male may experience a phase of hyper-masculinity during their teenage and young adult years as an attempt to purge their cross-gender identifications. This phase, where male-born individuals pursue stereotypically masculine activities, may in part drive the prevalence of military service among this population (Brown, 1988; McDuffie \& Brown, 2010). Indeed, the NTDS revealed that 20 percent of transgender and gender non-conforming respondents served in the military at some point in their life and many others wanted to serve, but they could not due to the ban. One respondent stated that he "scored high enough to go into the military and die for our country as a ranking officer-but [he] was denied because of [his] genitals not matching what [his] gender marker was on [his] license" (Harrison-Quintana \& Herman, 2012-2013, p. 8). Among those that are allowed to serve, transgender soldiers often endure a sense of alienation and find barriers in pronoun usage, dress and grooming standards, pressure to exceed performance standards (Parco, Levy, \& Spears, 2015). 
As a salient political issue, policies toward transgender people in the military service are likely significantly shaped by public opinion (e.g., Soroka \& Wlezien, 2010), but it is not clear from existing research how individuals form attitudes on this relatively new issue. Consistent with social role theory (e.g., Schneider \& Bos, 2019), we contend that attitudes toward societal gender roles and identity, along with personal experiences related to gender roles, significantly shape individual attitudes on transgender people serving in the military. This issue likely echoes prior experiences with policies related to a more inclusive military — be it the inclusion of gays and lesbians, women in combat roles, or even racial integration - that have drawn opposition based on the idea that inclusive combat units disrupt military readiness, which for the case of gays, lesbians, and women centers on how they are not cisgender heterosexual males and disrupt traditional ideals of the masculine order. Since trans-inclusive policies violate the traditional parity between sex and gender roles, it is likely that perception of one's own sex-to-gender role conformity and beliefs about social roles shape attitudes toward these policies. In addition, as an evolving issue, we expect that personal experiences related to gender-including contact with transgender people and personal experience with traditionally sex-segregated spaces, especially the military itself — should shape individual attitudes and preferences. Analyzing a 2015 national survey, we find that gender-related attitudes and personal experiences are, indeed, significant factors affecting attitudes toward military service by transgender individuals.

\section{Public Opinion on Military Service and LGBTQ People}

Relatively little empirical research has examined attitudes toward transgender people serving in the military, but there is some work on attitudes toward lesbian, gay and bisexual (LGB) soldiers. Public support for LGB soldiers serving openly in the military began gradually increasing in the 1970s and 1980s, with a sharper increase starting in the 1990s (Garretson, 2017; Flores, 2014). 
In the mid-1990s, opinions split nearly evenly on the issue, but by the early 2010s, substantial majorities (60\% or more) favored LGB military service. However, work comparing public attitudes toward gay rights to attitudes toward transgender rights finds that the factors that shape these sets of attitudes differ in important ways (Lewis et al., 2017). As such, increasing public support for LGB soldiers may not necessarily extend to transgender soldiers.

Unfortunately, polling about military service by transgender people has been sparse. In one of the few studies on this topic, Ender et al. (2016) compared the attitudes of civilian undergraduates, ROTC cadets, and military academy cadets. They found that civilian students were least supportive of a ban on openly transgender people serving in the military (16.6 percent), while academy cadets were most accepting of a ban (45.8 percent). Further, they found that men and ideologically conservative respondents were more supportive of a ban. Though the study relied on a limited sample, these predictive factors may extend to the general public, where military veterans, men, and ideological conservatives are more likely to support such a ban.

Indeed, the difference in attitudes between civilians and cadets mirrors the civil-military divide on political attitudes such as racial resentment, gay rights, and presidential candidates. Much of these gaps have has been attributed to self-selection, where those who volunteer for military service tend to have significantly different political identities, personality traits, demographics, and even genetics relative to civilians (e.g., Kellerman, 2014; Miles \& HaiderMarkel, 2018; Nteta \& Tarsi 2016), but socialization into the military may also play a factor (Bachman et al., 1987; Jackson et al., 2012). Military service entails powerful socialization mechanisms through boot camps and institutionalization at an age when people are still forming their political and social identities, as well as personality traits (Jennings \& Markus, 1977; Jackson et al., 2012). Critically for the issue of transgender military service, this socialization 
into a hierarchical structure emphasizing authoritarian values and traditions of sex-segregated spaces and roles may result in lower support for policies that defy a binary conception of gender, sex-segregation, and traditional gender roles. As such, we expected veterans of the military to be less likely to support transgender military service $\left(H_{1}\right)$.

\section{Public Opinion toward Transgender People}

Given the limited number of studies and limited applicability of some LGB focused research for public attitudes toward transgender people in the military, we also look to the literature on general attitudes toward transgender rights. This body of research has identified many factors that shape opinions about transgender people and a variety of related policies (e.g., nondiscrimination laws and hate crimes policies) which should extend to transgender military service. The first study on U.S. attitudes toward transgender people using a nationally representative sample showed that negative attitudes were associated with authoritarianism, ideological conservatism, anti-egalitarianism, and support of a binary conception of gender (Norton \& Herek, 2013). Other studies revealed negative correlations with traits such as disgust sensitivity and moral traditionalism, extending to attitudes toward transgender people, candidates, and related policies (Flores et al., 2018a; Jones et al., 2018; Miller et al., 2017; Taylor et al., 2018a).

Demographic characteristics, including education, race, sexual orientation, partisanship, ideology, and age, were also associated with attitudes toward transgender people (Castle 2018; Jones et al., 2018; Lewis et al., 2017; Norton \& Herek 2013; Tadlock et al., 2017). Generally, higher levels of educational attainment, racially identifying as white, Democratic partisanship, liberal ideological self-placement, and LGBTQ identification are each positively associated with pro-transgender positions. Conversely, age is negatively associated with these same positions. 
Religion, particularly religiosity as measured by the frequency of religious service attendance, is also a significant negative factor, though it may be a weaker factor compared to its role in shaping attitudes toward LGB people (Castle 2018; Lewis et al., 2017; Tadlock et al., 2017).

Another significant factor is interpersonal contact. In general, people view outgroups more favorably when they personally know someone from those groups (e.g., Allport, 1954). This effect may extend to contact with transgender people (Tadlock et al., 2017). Further, Flores (2015) found that contact with gays and lesbians induces a secondary contact effect on attitudes toward transgender rights (see also Lewis et al., 2017; Tadlock et al., 2017). Experimental work revealed that even "mere exposure" to images of transgender people can mitigate transphobia and prejudice in ways similar to parasocial contact (Flores et al., 2018a; 2018b).

\section{Sex, Gender Identification, and Gender Roles}

Perhaps not surprisingly, many studies show that sex, gender, and attitudes toward gender roles are important in shaping opinions toward transgender people and issues. A "gender gap" is common on many issues in the U.S. (e.g., Clark, 2017), likely because expressly gendered policies, including in areas that encompass historically sex-segregated institutions like the military, can affect men and women differently (Sapiro, 2003). Beyond clearly gendered policies, sex also serves as a cognitive cue to help form opinions and political attachments (Winter, 2005; Miller \& Conover, 2015). Nearly all studies found that women have more favorable attitudes than men about transgender people and their rights (e.g., Harrison \& Michelson, 2018; Lewis et al., 2017). In addition, masculinity and femininity often serve as a foundation for policies that involve the use of force (Haider-Markel \& Vieux, 2008) and women have been less supportive of military spending than men (Leal, 2005). As such, we expected that women are more likely to support transgender military service $\left(H_{2}\right)$. 
The underpinnings of an observed "gender gap" on attitudes toward transgender people in the military may be explained by social role theory. This theory asserts that gender stereotypes and expectations stem from traditional societal gender roles developed historically and based on biological differences. People are socialized into these roles from a young age and these roles subsequently shape their attitudes (Schneider \& Bos, 2019). Those with more traditional attitudes about the roles of men and women in society are likely to oppose policies that violate gender expectations (Tesler \& Sears, 2010; Young \& Nauta, 2013). Thus, when an individual considers a historically sex-segregated and gendered environment like the military, gender roles and identities should play prominent roles in opinions on transgender military service. Research on women serving in combat roles is consistent with these arguments. Indeed, opposition to women serving in combat roles was stronger among those who supported traditional gender roles (Iskra, 2007; Matthews et al., 2009; Young \& Nauta, 2013). And, as with attitudes toward LGB military service, men, conservatives, and more religious respondents were more likely to oppose women serving combat roles (Matthews et al., 2009; Segal, Kinzer, \& Woelfel, 1977; Young \& Nauta, 2013). Following this research, we expected people with more traditional views about gender roles to be less likely to support transgender military service $\left(H_{3}\right)$. Similarly, relatively more religious people should be less likely to support transgender military service $\left(H_{4}\right)$.

It is important to note that surveys often do not often address gender in ways that are more complex than simply denoting one's sex as a biologically based, binary variable (Sapiro, 2003). Yet, gender is a separate but related construct that may not align with biological sex: "masculinity and femininity correspond only fleetingly and roughly to 'male' and 'female"" (Beckwith, 2005, p. 131). The gender gap in political attitudes, for example, tends to diminish once gender identity is taken into account (Hatemi et al., 2012). Bittner \& Goodyear-Grant 
(2017) found that binary sex categories are appropriate for about three-quarters of Americans, but for one out of every four adults, binary categories do a poor job capturing a person's gender identity. Gender identification can be viewed as a social identity and people may categorize themselves as more or less conforming to their sex as assigned at birth. As a fundamental categorical schema for many people, "the self-categorization approach captures a more direct self-labeling of gender identity" (Wood \& Eagly, 2015, p. 464). This perspective incorporates social identity theory as it relates to social groups and prejudice (Tajfel, 1981). Those who have a strong sense of gender identity conformance — adhering to traditional gender roles - might be antagonistic toward transgender people that violate gender expectations and view them as an outgroup. In this study, we expected people with more congruent gender identities to be less likely to support transgender military service $\left(H_{5}\right)$.

Further, sex, gender, and views on gender roles may condition the effects of other factors. For example, Nagoshi et al. (2008) found transphobia to be correlated with homophobia, authoritarianism, and religious fundamentalism. However, when homophobia was controlled for, authoritarianism and fundamentalism predicted transphobia only for women, but not for men. In this policy area, we expect the "gender gap" to shrink for people who hold less traditional gender role views. For these people, gender is likely a less important identity construct, leading both men and women with less traditional gender role views to hold relatively similar attitudes toward transgender military service. In other words, we expected the effect of sex to be smaller for people with less traditional views about societal gender roles $\left(H_{6}\right)$. Likewise, this conditional effect may extend to other characteristics that reflect traditional values, such as religiosity. Since adherence to traditional gender roles is prominent in many religions, the effect of sex should be larger for relatively more religious people $\left(\mathrm{H}_{7}\right)$. There may also be a conditional effect of sex 
across gender identities, where those with more sex-gender congruent identities have larger differences between the sexes $\left(H_{8}\right)$. Indeed, research on sex-segregation policies in athletics found that the effects of sex were contingent on gender identity, attitudes toward gender roles, and sports fandom (Taylor, et al., 2018b). More traditional gender identities and attitudes toward gender roles increased the gap between the sexes, but stronger sports fandom decreased this difference. With the traditional culture and tradition of sex-segregation in the military, we expect similar sex-interactive effects on attitudes toward transgender military service.

\section{Data \& Methods}

To test the hypotheses enumerated in the previous section, while also accounting for the effects of psychological traits, interpersonal contact with LGBT people, demographics, and political orientations, we analyzed a nationally representative survey of 1,020 American adults fielded by the large research firm GfK, via their KnowledgePanel, on October 9-11, 2015. The survey was fielded prior to the repeal of the ban on transgender service members. The survey was administered online to a nationally representative panel constructed using address-based probability sampling to overcome coverage bias issues common in landline telephone-based polling (e.g., the rise of cell phone only households). To further reduce sampling bias, selected respondents in non-Internet households were provided a computer and online access. This sample differs from non-probability online surveys since respondents do not opt-in to the panel, reducing demographic and political biases common in opt-in surveys (Yeager et al., 2011). Thus, this sampling methodology provides a representative national sample with better coverage than surveys that rely on traditional approaches (Dennis, 2010). ${ }^{3}$ Further, all the analyses used GfK's proprietary weights compensating for demographic non-response and probabilities of selection. ${ }^{4}$ 
Missing data values were estimated via multiple imputation rather than allowing for list-wise deletion, which systematically biases data analyses (King et al., 2001).

The dependent variable for the analyses gauged support for allowing transgender people to serve openly in the military. The survey included batteries of items asking respondents whether they strongly agreed, agreed, neither agreed nor disagreed, disagreed, or strongly disagreed with a set of statements, two of which addressed military service. The first statement had a positive valence, "Allowing transgender people to serve openly in the military." As Figure 1 shows, 25 percent of respondents disagreed or strongly disagreed with this statement, 39 percent agreed or strongly agreed, and 36 percent reported neither agreeing nor disagreeing. The second statement had a negative valence, "Transgender people should not be allowed to serve openly in the military." Forty-two percent disagreed or strongly disagreed with this statement, 22 percent agreed or strongly agreed, and 36 percent reported neither agreeing nor disagreeing. The two items were strongly correlated $(r=-0.78)$ and a clear plurality supported allowing transgender people to serve in the military, though more than a third of the sample reported no clear opinion. Responses were recoded such that higher scores indicated support for allowing transgender people to serve in the military. This allowed the items to be combined into a single variable. For the analyses, we used a respondent's mean response on these two items as the dependent variable. ${ }^{5}$ Scores ranged from 1 to 5 , with a mean of $3.2(\mathrm{SD}=1.1){ }^{6}$

\section{[Insert Figure 1 about here]}

We modeled support for allowing transgender people to serve in the military as a function of a number of independent variables measuring factors identified in the literature review, including demographics, psychological traits, political attitudes, and personal experience. ${ }^{7}$ Sex was assessed with a traditional, dichotomous indicator of female versus male respondents $\left(H_{2}\right)$. 
Beyond this key demographic factor, the models also account for educational attainment, race (non-white/white), LGBT identification, and age (on the logarithmic scale).

The models included two gender constructs. First, gender identity congruence $\left(H_{5}\right)$ was measured with items from the Adult Gender Identity Scale that gauge respondents' perception of their own masculinity or femininity (Hatemi et al., 2012). Depending on their reported sex, respondents were asked whether they agreed (0) or disagreed (1) with the following statements:

\section{Women}

- In many ways, I feel more similar to men than women.

- I feel like part of me is female and part of me is male.

- I often think that I would rather be a man.

- People think that I should act more feminine than I do.

Men

- In many ways, I feel more similar to women than men.

- I feel like part of me is male and part of me is female.

- I often think that I would rather be a woman.

- I don't feel very masculine.

An additive scale of these items was created, with higher scores indicating gender identities that are more congruent with a person's sex as assigned at birth. ${ }^{8}$ The mean score was $3.6(\mathrm{SD}=0.8)$, with 77 percent of the sample reporting the highest level of gender identity congruence (4). Another 13 percent of the sample had a score of 3 . This high degree of sex-gender identity congruence is not surprising given the relatively low population of people who identify as transgender in the U.S. (Flores et al., 2016). Still, nearly 10 percent of the sample reported some sex-gender identity non-congruence (i.e., scored less than 3).

Second, we measured attitudes toward gender roles with a Gender Traditionalism Scale $\left(H_{3}\right)$ derived from four items in Kerr \& Holden's (1996) Gender Role Belief Scale:

- The initiative in courtship should usually come from the man.

- There are some professions and types of businesses that are more suitable for men than women.

- It bothers me more to see a woman who is pushy than a man who is pushy.

- It is disrespectful for a man to swear in the presence of a lady. 
The items used a 7-point Likert response, with higher scores indicating more traditional gender roles. Responses were added together in an index with a possible range of 0 to $24 .{ }^{9}$ The index had modal score of 12 , a mean of $12.5(\mathrm{SD}=4.9)$, and a relatively normal distribution.

Key experiential factors in the model include interpersonal contact and prior military service. Interpersonal contact was accounted for with two indicators of whether respondents know a family member, a close friend, or an acquaintance who is gay/lesbian or transgender. 72 percent of the sample reported knowing a gay man or lesbian, but just 14.6 percent reported knowing a transgender person. The effect of military service was assessed with a binary indicator of whether a respondent is a military veteran $\left(H_{l}\right)$, accounting for 13.5 percent of the sample.

The models also included psychological traits. Authoritarianism was measured with an additive scale of four items taken from the American National Election Studies (ANES) (DeBell et al., 2011). ${ }^{10}$ Ranging from 0 to 4 , higher values indicated greater authoritarianism. Disgust sensitivity was controlled for via an additive scale of four items based on the concept of contamination disgust (Haidt, McCauley, \& Rozin, 1994). This scale ranges from 0 to 12 with higher values indicating more disgust sensitivity. ${ }^{11}$ Moral traditionalism ${ }^{12}$ and egalitarianism ${ }^{13}$ were each assessed with an indices derived from the ANES. After recoding items to ensure uniformity of direction, both scales have possible ranges between 0 and 16, with higher scores representing greater levels of the construct.

Several other relevant factors were accounted for in the analyses. Religiosity is gauged with a six-point scale of religious service attendance $\left(H_{4}\right)$, ranging from "more than once a week" to "never." ${ }^{14}$ Conservative religious adherence was measured by self-identification as a born-again or evangelical Christian. Lastly, the models included seven-point scales of ideology and partisanship. Higher scores on the ideology measure indicate greater conservatism while a higher score on the partisanship shows greater adherence to the Republican Party. 
From this base specification, we also estimated models to assess interactions with sex, including interactions with gender role traditionalism $\left(H_{6}\right)$, religiosity $(H 7)$, and gender identity congruence $\left(H_{8}\right)$. This allowed us to test whether the effect of sex is conditioned by these factors. In addition, to more broadly explore possible conditional effects of the factors by sex, we split the model by sex and estimated two seemingly unrelated regressions (SUR), which enabled us to conduct statistical tests of differences in coefficients for all the independent variables by sex.

\section{Results}

The results from OLS regressions of support for military service by transgender people are presented in Table 1. Model 1 provided support for both $H_{1}$ and $H_{2}$. Veterans, on average, were less supportive of transgender people serving in the military by about 10 percent of a standard deviation. Though this effect is not large, its significance across all models is striking given the number of demographic and psychological variables in the models. Women, meanwhile, were more supportive by a similar magnitude. However, Models 2-4 suggested that the effect of sex was conditioned by gender role orientations and attitudes.

[Insert Table 1 about here]

Contrary to $H_{5}$, gender identity congruence seems to have no effect, but attitudes toward gender roles significantly shaped opinions about transgender soldiers as predicted by $H_{3}$. A standard deviation shift (about five points) towards more traditional views about gender roles decreases support by about 0.2 points. Compared to those with the most nontraditional views about gender roles, people with the most traditional gender views (24) had a mean support level about one point lower, on average. Disgust sensitivity also had a statistically significant effect. The most sensitive respondents reported roughly 0.4 points lower support, on average, than the least sensitive. The largest effect in the model, according to standardized coefficients, was moral 
traditionalism. A standard deviation increase in moral traditionalism (3.6) was associated with a 0.3 point decrease in support. A shift from the minimum to the maximum moral traditionalism score reduced support by 1.4 points. Egalitarianism, not surprisingly, was significantly associated with support for transgender people's military service. The most egalitarian respondents were nearly one point more supportive than those with the least egalitarian views.

Several other variables also had significant effects. Both interpersonal contact coefficients were statistically significant and positive. Yet, knowing a transgender person had nearly twice as large an effect as knowing a gay or lesbian person. Though religious service attendance was statistically significant $\left(H_{4}\right)$, born-again or evangelical adherents reported significantly lower levels of support for transgender military service by about 0.3 points on average. Age was also a significant factor, with older respondents reporting less supportive attitudes. Compared to an 18-year-old respondent, a 65-year-old respondent was about 0.2 points less supportive, on average. Last, partisanship showed a marginally significant effect. A strong Republican was 0.15 points less supportive on average compared to a strong Democrat.

\section{Interaction Effects}

The next three models in Table 1 include interactions with the binary sex variable. Though these specifications reveal conditional effects of sex, the results of the other factors remained largely the same, with a consistent model fit of about 0.465. First, Model 2 tested a conditional effect of sex based on respondents' gender identity congruence. Though the coefficient on the interaction was not statistically significant, an interactive effect consistent with $H_{8}$ is evident from the marginal effects presented in Figure 2. For respondents with relatively incongruent gender identities $(<3)$, about ten percent of the sample, sex was not a significant factor. However, for 
those respondents with more congruent gender identities, women were significantly more supportive than men by about a tenth of a point on average.

[Insert Figure 2 about here]

Next, Model 3 tested the interaction between sex and gender traditionalism. Again, plotting the marginal effects in Figure 3 revealed significant variation in the effect of sex across the values of gender traditionalism $\left(H_{6}\right)$. For respondents with the most nontraditional views about gender roles, there was no significant difference between the sexes in attitudes toward military service by transgender people. Yet, for respondents with more traditional views, the difference between men and women increased, reaching marginal levels of statistical significance $(p<0.10)$. Women who held more traditional gender role attitudes were relatively more supportive of military service by transgender people than men with those same views. This difference became marginally significant at around 8 on the gender role scale and the gap increased from about 0.1 to 0.17 points for those with the most traditional gender views. [Insert Figure 3 about here]

Last, as seen in Figure 4, the interaction between sex and religiosity in Model 4 also revealed a conditional effect of sex. In this model, the coefficient for the sex variable was positive and statistically significant. For respondents who attend religious services more than once a week there was a large (nearly 0.2 points) and statistically significant difference between men and women, with women significantly more supportive of military service by transgender people than men. Consistent with $H_{7}$, the gender gap, however, decreased as respondents attend church less often and disappeared entirely for those that never attend religious services.

[Insert Figure 4 about here] 
The results from Models 2-4 suggest that the base model oversimplified the effect of sex on attitudes toward military service by transgender individuals. Among respondents with more gender congruent identities, traditional views on gender roles, and higher religiosity, sex was a significant factor in shaping attitudes. Yet, it was not a significant factor for those who had less congruent gender identities, less traditional views about gender roles, and were less religious.

Interestingly, while the models presented in Table 1 showed a conditional effect of sex, the reverse interactive effect was not apparent. The effects of gender identity congruence, gender traditionalism, or religiosity did not vary between men and women. To more fully assess whether the factors vary by sex, we estimated a SUR model split by sex to allow for statistical tests of the equality of coefficients across equations (reported in the online appendix). For most variables, the effects on attitudes toward military service by transgender people were the same for men and women. Indeed, only LGBT identification had a statistically significant difference according to $\chi^{2}$ tests. Yet, a few other factors displayed differences worth mentioning. First, veteran status did not have a significant effect for men, but female veterans reported less support for military service by transgender individuals than their civilian counterparts. However, this result was based on just 18 female veterans in the sample, so we are cautious about this possible effect. Next, the disgust sensitivity coefficient for men was twice the size of the coefficient for women. Also, respondent LGB interpersonal contact was not a significant factor for men, but was for women. Similarly, respondent LGBT identity and age were significant factors shaping women's attitudes, but not for men. In all, the "gender gap" in support for military service by transgender people may derive from the differences in the effects of just a handful of factors.

\section{Conclusion}


The ongoing legal and political struggles over transgender people in the military underscore the importance of public perceptions on this issue. As Mucciaroni notes, transgender inclusion would transform "the institutions because they are no longer bastions of ... privilege based upon fixed gender assignment” (2017, p. 541). As with DADT, “opponents of LGBTQ rights fought so hard to exclude queers from the military and marriage is precisely because they used these widely cherished institutions to enforce heteronormativity and stigmatize those who refuse to conform to it" (Mucciaroni 2017, p. 541). Indeed, we showed that respondents with a stake in protecting the status quo in the military and society - men, veterans, religious conservatives, and traditionalists - were all more likely to oppose this transgender inclusive policy.

Yet, we also found the effect of sex to be dependent on gender identity congruence, traditional gender norms, and religiosity. Among those with the most conservative and traditional perspectives, men and women reported significantly different attitudes, but these differences declined for more respondents with less traditional gender role orientations. These nuanced effects are particularly striking when placed in the current political context of large gender gaps on many political issues and shifting attitudes about gender roles in society and the armed forces (e.g., Burns \& Gallagher 2010; Carroll \& Fox, 2018). This is consistent with Hatemi et al. (2012), who contend that the effects of gender identity are magnified in contexts of social and political hierarchy related to sex. In this case, it appeared that attitudes toward military service by transgender people were significantly shaped by gender roles and identities, conditioning traditional political factors that often shape public opinion. Disentangling these factors "adds theoretical coherence, normative value, and possibly predictive power to the analyses of political preferences" (Hatemi et al., 2012, p. 90). As such, significant opposition to a ban on transgender 
people in the military extends beyond the traditional liberal-conservative and traditionalprogressive cleavages, with sex and gender roles acting as significant conditioning factors.

Understanding the factors that shape public opinion regarding the inclusion of groups who have been historically excluded from the military is also important because it likely affects the willingness of outgroups to both participate in the military and to continue their service beyond an initial commitment. In their study of women in the military, Matthews et al. argue that "social attitudes may impact the propensity of women to volunteer for military service of any type and, if serving, affect the likelihood of remaining in the military beyond the initial service commitment" (2009, p. 250). Thus, it is important to consider the extent to which public attitudes may affect transgender individuals' willingness to build a career in the military. Though transgender people have shown high rates of military service, negative public opinion may be limiting the ability of the military to retain these service members.

Further, public opinion is a powerful factor shaping public policies themselves. As attitudes toward LGBTQ rights shifted in recent decades, policies that provide protections and enhance inclusiveness have followed. Indeed, public opinion has been a major factor shaping the legalization of same-sex marriage and the passage of nondiscrimination laws (Lewis \& Jacobsmeier, 2017; Taylor et al., 2012; Taylor, Lewis, \& Haider-Markel, 2018). In addition, the repeal of DADT was certainly affected by an ever more tolerant public, driven in part by increasing amounts of, "mass information about homosexuality and awareness of gays and lesbians" (Brewer, 2003, p. 1217). Further, as public policies become more inclusive, public opinion may, in turn, become more supportive of LGBTQ rights (e.g., Flores \& Barclay, 2016; Kreitzer, Hamilton, \& Tolbert, 2014). 
This begs the question of whether similar dynamics are in play with transgender people, given the heightened awareness of them through popular culture, the political environment, and interpersonal contact (Tadlock et al., 2018). Indeed, Garretson notes that "those who were marginalized — or potentially risked marginalization — because of their ... gender identity" serve as the medium through which public opinion changes $(2017$, p. 263). Stories about transgender people seeking to serve their country only to be turned away, especially if they are removed from the military, will likely create a narrative that resonates with the public. Thus, as the public becomes more aware of potential or actual transgender service members, and transgender people more broadly, they will likely increase support for inclusion in the armed forces. Indeed, recent polling suggests that following the Trump Administration's ban on transgender military service, Republican support for allowing transgender people to serve has actually increased (Blake 2019). Though concerns about organizational change in the military and its impact on military readiness may remain, changing societal attitudes toward gender roles and decreasing sex-segregation in the military will only increase support for inclusion of transgender people in the military. 


\section{Endnotes}

${ }^{1}$ At least 18 countries allowed transgender to serve in the military (Polchar et al., 2014).

${ }^{2}$ The National Transgender Discrimination Survey is a purposive sample of transgender and gender nonconforming adults in the United States. Due to its sampling design, the survey may not necessarily be generalizable to all transgender and gender non-conforming adults in the United States.

${ }^{3}$ For details of the KnowledgePanel methodology, see https://www.gfk.com/fileadmin/user_upload/dyna_content/US/documents/KnowledgePanel_-

_A_Methodological_Overview.pdf. Due to the improved coverage of this approach, the KnowledgePanel has been increasingly utilized in studies published in scholarly journals across the social and natural sciences.

${ }^{4}$ The weights are based on age, sex, education, race, household income, met/non-met status, internet status, and geographic region.

${ }^{5}$ Using the mean is functionally equivalent to an additive index, but allows for a more clear interpretation of the measure that corresponds to the original 5 point agree-disagree scale.

${ }^{6}$ Modeling the two items separately does not significantly change the results of the analysis.

${ }^{7}$ Descriptive statistics for all variables are presented in the online appendix.

${ }^{8}$ For the four items for women, $\alpha=0.56$. For men, $\alpha=0.59$.

${ }^{9}$ For the four items comprising the gender traditionalism scale, $\alpha=.73$.

${ }^{10}$ Each item in this scale poses two traits to respondents, who are then asked which is "more important for children to have." The items include, "respect for elders" versus "independence," "good manners" versus "curiosity," "obedience" versus "self-reliance," and "well behaved" versus "being considerate." For these four items, $\alpha=.61$. ${ }^{11}$ Respondents were provided a four-point response scale to each statement ranging from "extremely like me" to "not like me." The statements included, "I never let any part of my body touch the toilet seat in a public washroom;" "I probably would not go to my favorite restaurant if I found out that the cook had a cold;" "I use hand sanitizer on a daily basis;" and "I am perfectly fine with drinking water from the same cup as an acquaintance." Response recoded so that higher values indicated more disgust sensitivity. For these items, $\alpha=.59$.

${ }^{12}$ Each item asked respondents on a five-point agree-disagree scale to respond to the following items: "The world is always changing and we should adjust our view of moral behavior to those changes;" "The newer lifestyles are contributing to the breakdown of our society;" "We should be more tolerant of people who choose to live according to their own moral standards, even if they are very different from our own;" and "This country would have many fewer problems if there were more emphasis on traditional family ties." For these items, $\alpha=.79$.

${ }^{13}$ Each item asked respondents on a five-point agree-disagree scale to respond to the following items: "We have gone too far in pushing equal rights in this country;" "This country would be better off if we worried less about how equal people are;" "It is not really that big a problem if some people have more of a chance in life than others;" and "If people were treated more equally in this country, we would have many fewer problems." For the four items comprising the egalitarianism scale, $\alpha=.80$. 
${ }^{14}$ The six religious attendance categories are "more than once a week," "once a week," "once or twice a month," "a few times a year," "seldom," and "never." 


\section{References}

Allport, G. (1954). The Nature of Prejudice. Reading, MA: Addison Wesley.

Beckwith, K. (2005). A Common Language of Gender. Politics \& Gender, 1, 128-137.

Bittner, A., \& Goodyear-Grant, E. (2017). Sex Isn't Gender: Reforming Concepts and Measurements in the Study of Public Opinion. Political Behavior, 39, 1019-1041.

Blake, A. (2019). Trump's transgender military ban is losing support even in his own party. The Washington Post: The Fix. 11 June. Accessed: https://www.washingtonpost.com/politics/2019/06/11/trumpstransgender-military-ban-is-losing-even-his-own-party/?utm_term=.0de0a008d4e8

Brewer, P. (2003). The Shifting Foundations of Public Opinion about Gay Rights. The Journal of Politics, 65, 1208-1220.

Bromwich, J. (2017, July 26). How U.S. Military Policy on Transgender Personnel Changed Under Obama. The New York Times. https://www.nytimes.com/2017/07/26/us/politics/trans-military-trump-timeline.html

Brown, G.R.. (1988). Transsexuals in the military: Flight into hypermasculinity. Archives of Sexual Behavior, 17(6): 527-537.

Burns, N., \& Gallagher, K. (2010). Public opinion on gender issues: The politics of equity and roles. Annual Review of Political Science, 13, 425-443.

Carroll, S. J., \& Fox, R. L. (Eds.). (2018). Gender and elections: Shaping the future of American politics. Cambridge University Press.

Castle, J, (2018). New Fronts in the Culture Wars? Religion, Partisanship, and Polarization on Religious Liberty and Transgender Rights in the United States. American Politics Research. (online first) https://doi.org/10.1177/1532673X18818169

Clark, A. (2017). Updating the Gender Gap(s): A Multilevel Approach to What Underpins Changing Cultural Attitudes. Politics \& Gender, 13, 26-56.

DeBell, M., Wilson, C., Segura, G., Jackman, S., \& Hutchings, V. (2011). Methodology Report and User's Guide for the ANES 2010-2012 Evaluations of Government and Society Study, Palo Alto, CA: Stanford University.

Dennis, J. M. (2010). KnowledgePanel: Processes and procedures contributing to sample representativeness and tests for self-selection bias. Alexandria, VA: GfK Knowledge Networks. Available at http://www.knowledgenetworks.com/ganp/docs/knowledgepanelr-statistical-methods-note.pdf.

Ender, M., Rohall, D., \& Matthews, M. (2016). Cadet and Civilian Undergraduate Attitudes toward Transgender People: A Research Note. Armed Forces \& Society, 42, 427-435.

Flores, A. R. (2014, November). National Trends in Public Opinion on LGBT Rights in the United States. https://escholarship.org/uc/item/72t8q7pg 
Flores, A. R. (2015). Attitudes toward Transgender Rights: Perceived Knowledge and Secondary Interpersonal Contact. Politics, Groups, and Identities, 3, 398-416.

Flores, A. R., \& Barclay, S. (2016). Backlash, consensus, legitimacy, or polarization: The effect of same-sex marriage policy on mass attitudes." Political Research Quarterly, 69(1), 43-56.

Flores, A R., Herman, J., Gates, G., \& Brown, T. (2016, June). How Many Adults Identify as Transgender in the United States? http://williamsinstitute.law.ucla.edu/wp-content/uploads/How-Many-Adults-Identifyas-Transgender-in-the-United-States.pdf

Flores, A. R., Haider-Markel, D., Lewis, D., Miller, P., Tadlock, B., \& Taylor, J. (2018a). Challenged Expectations: Mere Exposure Effects on Attitudes about Transgender People and Rights. Political Psychology, 39, 197-216.

Flores, A. R., Haider-Markel, D., Lewis, D., Miller, P., Tadlock, B., \& Taylor, J. (2018b). Transgender Prejudice Reduction and Opinions on Transgender Rights: Results from a Mediation Analysis on Experimental Data. Research \& Politics, March 20. https://doi.org/10.1177/2053168018764945

Garretson, J. (2017). The How, Why, and Who of LGBTQ 'Victory': A Critical Examination of Change in Public Attitudes Involving LGBTQ People. In M. Brettschneider, S. Burgess, \& C. Keating (Eds.), LGBTQ Politics: A Critical Reader (pp. 252-269). New York: New York University Press.

Gates, G., \& Herman, J. (2014, May). Transgender Military Service in the United States. https://williamsinstitute.law.ucla.edu/research/military-related/us-transgender-military-service/

Haider-Markel, D., \& Vieux, A. (2008). Gender and Conditional Support for Torture in the War on Terror. Politics \& Gender, 4, 5-33.

Haidt, J., McCauley, C., \& Rozin, P. (1994). Individual Differences in Sensitivity to Disgust: A Scale Sampling Seven Domains of Disgust Elicitors. Personality and Individual Differences, 16, 701-713.

Harrison, B., \& Michelson, M. (2018). Gender, Masculinity Threat, and Support for Transgender Rights: An Experimental Study. Sex Roles: A Journal of Research, https://doi.org/10.1007/s11199-018-0916-6

Harrison-Quintana, J., \& Herman, J. (2012-2013). Still Serving in Silence: Transgender Service Members and Veterans in the National Transgender Discrimination Survey. LGBTQ Policy Journal at the Harvard Kennedy School, 3, 39-52.

Hatemi, P., McDermott, R., Bailey, J., \& Martin, N. (2012). The Different Effects of Gender and Sex on Vote Choice. Political Research Quarterly, 65, 76-92.

Iskra, D. (2007). Attitudes toward expanding roles for Navy women at sea: Results of a content analysis. Armed Forces \& Society, 33, 203-223.

Jackson, J., Thoemmes, F., Jonkmann, K., Lüdtke, O., \& Trautwein, U. (2012). Military training and personality trait development: Does the military make the man, or does the man make the military?. Psychological science, 23(3), 270-277.

Jenning, M., \& Markus, G. (1977). The effect of military service on political attitudes: A panel study. American Political Science Review, 71(1), 131-147. 
Jones, P., Brewer, P., Young, D., Lambe, J., \& Hoffman, L. (2018). Explaining Public Opinion toward Transgender People, Rights, and Candidates. Public Opinion Quarterly, 82, 252-278.

Kellermann, M. (2014). Self-selection and opposition to gay rights among military career-seekers. Politics, Groups, and Identities, 2(3), 443-458.

Kerr, P., \& Holden, R. (1996). Development of the Gender Role Beliefs Scale (GRBS). Journal Of Social Behavior \& Personality, 11, 3-16.

King, G., Honaker, J., Joseph, A., \& Scheve, K. (2001). Analyzing incomplete political science data: An alternative algorithm for multiple imputation. American Political Science Review, 95(1), 49-69.

Kreitzer, R., Hamilton, A., \& Tolbert, C. (2014). Does policy adoption change opinions on minority rights? The effects of legalizing same-sex marriage. Political Research Quarterly, 67(4), 795-808.

Leal, D. (2005). American Public Opinion Toward the Military: Differences by Race, Class and Gender. Armed Forces \& Society 32, 123-138.

Lewis, D., Flores, A., Haider-Markel, D., Miller, P., Tadlock, B., \& Taylor, J. (2017). Degrees of Acceptance: Variation in Attitudes toward Segments of the LGBT Community. Political Research Quarterly, 70, 861875.

Lewis, D., \& Jacobsmeier, M. (2017). Evaluating Policy Representation with Dynamic MRP Estimates: Direct Democracy and Same-Sex Relationship Policies in the U.S. State Politics \& Policy Quarterly, 17, 441464.

Matthews, M., Ender, M., Laurence, J., \& Rohall, D. (2009). Role of Group Affiliation and Gender on Attitudes Toward Women in the Military. Military Psychology, 21, 241-251.

McDuffie, E., \& Brown, G.R. (2010). 70 U.S. Veterans with gender identity disturbances: A descriptive study. International Journal of Transgenderism, 12(1): 21-30.

Miles, M., \& Haider-Markel, D. (2018). Personality and Genetic Associations With Military Service. Armed Forces \& Society, 0095327X18765449.

Miller, P., \& Conover, P. (2015). Why Partisan Warriors Don't Listen: The Gendered Dynamics of Intergroup Anxiety and Partisan Conflict. Politics, Groups, and Identities, 3, 21-39.

Miller, P., Flores, A., Haider-Markel, D., Lewis, D., Tadlock, B., \& Taylor, J. (2017). Transgender Politics as Body Politics: Effects of Disgust Sensitivity and Authoritarianism on Transgender Rights Attitudes. Politics, Groups, and Identities, 5, 4-24.

Mucciaroni, G. (2017). Whither the LGBTQ Movement in a Post-Civil Rights Era? In M. Brettschneider, S. Burgess, \& C. Keating (Eds.) LGBTQ Politics: A Critical Reader (pp. 525-544). New York: New York University Press.

Nagoshi, J., Adams, K., Terrell, H., Hill, E., Brzuzy, S., \& Nagoshi, C. (2008). Gender Differences in Correlates of Homophobia and Transphobia. Sex Roles, 59, 521-531.

Norton, A., \& Herek, G. (2013). Heterosexuals' Attitudes Toward Transgender People: Findings from a National Probability Sample of U.S. Adults. Sex Roles, 68, 738-753. 
Nteta, T., \& Tarsi, M. (2016). Self-selection versus socialization revisited: Military service, racial resentment, and generational membership. Armed Forces \& Society, 42(2), 362-385.

Okros, A., \& Scott, D. (2015). Gender Identity in the Canadian Forces: A Review of Possible Impacts on Operational Effectiveness. Armed Forces \& Society, 41(2), 243-256.

Palm Center. (2018, March 27). Breaking Down the March 23, 2018 Transgender Military Ban. https://www.palmcenter.org/publication/breaking-down-the-march-23-2018-transgender-military-ban/

Parco, J, Levy, D., \& Spears, S. (2015). Transgender Military Personnel in the Post-DADT Repeal Era: A Phenomenological Study. Armed Forces \& Society 41(2), 221-242

Polchar, J., Sweijs, T., Marten, P., \& Gladiga, J. (2014). LGBT Military Personnel: A Strategic Vision for Inclusion. The Hague, the Netherlands: The Hague Centre for Strategic Studies.

Sapiro, V. (2003). Theorizing Gender in Political Psychology Research. In D. Sears, L. Huddy, \& R. Jervis (Eds.) Oxford Handbook of Political Psychology (pp. 601-634). New York: Oxford University Press.

Schneider, M., \& Bos, A. (2019). The Application of Social Roles Theory to the Study of Gender in Politics. Political Psychology, 40 (1), 173-213.

Segal, D., Scott Kinzer, N., \& Woelfel, J. (1977). The concept of citizenship and attitudes toward women in combat. Sex Roles, 3, 469-477.

Sonne, P., \& Marimow, A. (2019, March 13). Military to begin enforcing Trump's restrictions on transgender troops. Washington Post. Accessed from https://www.washingtonpost.com/world/nationalsecurity/military-to-begin-enforcing-restrictions-on-trumps-transgender-troops/2019/03/13/cf2a05304587-11e9-9726-50f151ab44b9_story.html?noredirect=on\&utm_term=.32cff8de3132

Soroka, S. N., \& Wlezien, C. (2010). Degrees of Democracy: Politics, Public Opinion, and Policy. New York, NY: Cambridge University Press.

Tadlock, B., Flores, A., Haider-Markel, D., Lewis, D., Miller, P., \& Taylor, J. (2017). Testing Contact Theory and Attitudes on Transgender Rights. Public Opinion Quarterly, 81, 956-972.

Tajfel, H. (1981). Human Groups and Social Categories: Studies in Social Psychology. New York: Cambridge University Press.

Taylor, J., \& Lewis, D. (2014) The Advocacy Coalition Framework and Transgender Inclusion in LGBT Rights Activism. In J. Taylor \& D. (Eds.) Transgender Rights and Politics (pp. 108-134). Ann Arbor, MI: University of Michigan Press.

Taylor, J., Lewis, D., \& Haider-Markel, D. (2018). The Remarkable Rise of Transgender Rights. Ann Arbor, MI: University of Michigan Press.

Taylor, J., Lewis, D., Haider-Markel, D., Flores, A., Miller, P., \& Tadlock, B. (2018a). The Factors Underlying Public Opinion of Transgender Rights. In J. Taylor, D. Lewis, \& D. Haider-Markel (Eds.) The Remarkable Rise of Transgender Rights (pp. 107-127). Ann Arbor, MI: University of Michigan Press. 
Taylor, J., Lewis, D., Haider-Markel, D., Flores, A., Miller, P., \& Tadlock, B. (2018b). Public Attitudes about Transgender Participation in Athletics: The Role of Gender. Southern Political Science Association Annual Meeting, New Orleans (LA), January 6, 2018.

Taylor, J., Lewis, D., Jacobsmeier, M., \& DiSarro, B. (2012). Content and Complexity in Policy Reinvention and Diffusion: Gay and Transgender-Inclusive Laws against Discrimination. State Politics \& Policy Quarterly, 12, 92-115.

Tesler, M., and Sears, D. O. (2010). Obama's Race: The 2008 Election and the Dream of a Post-Racial America. Chicago, IL: Chicago University Press.

The Economist. (2017, July 27). Why the President Wants to Ban Trans People from Serving. https://www.economist.com/united-states/2017/07/27/why-the-president-wants-to-ban-trans-people-fromserving

Winter, N. (2005). Framing Gender: Political Rhetoric, Gender Schemas, and Public Opinion on U.S. Health Care Reform. Politics \& Gender, 1, 453-480.

Wood, W., \& Eagly, A. (2015). Two Traditions of Research on Gender Identity. Sex Roles, 73, 461-473.

Yeager, D. S., Krosnick, J. A., Chang, L., Javitz, H. S., Levendusky, M. S., Simpser, A., \& Wang, R. (2011). Comparing the accuracy of RDD telephone surveys and internet surveys conducted with probability and non-probability samples. Public Opinion Quarterly, 75(4), 709-747.

Young, L., \& Nauta, M. (2013). Sexism as a predictor of attitudes toward women in the military and in combat. Military Psychology, 25, 166-171. 


\section{Tables}

Table 1. Support for Allowing Transgender People to Serve in the Military

\begin{tabular}{|c|c|c|c|c|c|c|c|c|}
\hline \multirow[b]{2}{*}{ Variable } & \multicolumn{2}{|c|}{ Model 1} & \multicolumn{2}{|c|}{$\underline{\text { Model } 2}$} & \multicolumn{2}{|c|}{$\underline{\text { Model } 3}$} & \multicolumn{2}{|c|}{ Model 4} \\
\hline & $\mathbf{b}_{\mathbf{i}}$ & $\mathbf{S E}_{\mathbf{b}}$ & $\mathbf{b}_{\mathbf{i}}$ & $\mathbf{S E}_{b}$ & $\mathbf{b}_{\mathbf{i}}$ & $\mathbf{S E}_{b}$ & $\mathbf{b}_{\mathbf{i}}$ & $\mathbf{S E}_{\mathbf{b}}$ \\
\hline Veteran & $-0.135 *$ & $(0.081)$ & $-0.134 \#$ & $(0.082)$ & $-0.132 \#$ & $(0.082)$ & $-0.134 *$ & $(0.081)$ \\
\hline Sex (female) & $0.119 *$ & $(0.056)$ & 0.245 & $(0.262)$ & 0.059 & $(0.144)$ & $0.197 *$ & $(0.108)$ \\
\hline Sex X Gender ID Congruence & ------ & ------ & -0.034 & $(0.070)$ & ------ & ------ & ------ & ------ \\
\hline Sex X Gender Traditionalism & ------ & ------ & ------ & ------ & 0.005 & $(0.011)$ & ------ & ------ \\
\hline Sex X Religiosity & ------ & ------ & ------ & ------ & ------ & ------ & -0.025 & $(0.030)$ \\
\hline Gender ID Congruence & -0.040 & $(0.035)$ & -0.017 & $(0.058)$ & -0.040 & $(0.035)$ & -0.043 & $(0.035)$ \\
\hline Gender Traditionalism & $-0.040 * * *$ & $(0.007)$ & $-0.040 * * *$ & $(0.007)$ & $-0.043 * * *$ & $(0.009)$ & $-0.040 * * *$ & $(0.007)$ \\
\hline Authoritarianism & -0.010 & $(0.023)$ & -0.010 & $(0.023)$ & -0.010 & $(0.023)$ & -0.010 & $(0.023)$ \\
\hline Disgust Sensitivity & $-0.031 * * *$ & $(0.009)$ & $-0.031 * * *$ & $(0.009)$ & $-0.031 * * *$ & $(0.009)$ & $-0.031 * * *$ & $(0.009)$ \\
\hline Moral Traditionalism & $-0.090 * * *$ & $(0.011)$ & $-0.090 * * *$ & $(0.011)$ & $-0.090 * * *$ & $(0.011)$ & $-0.090 * * *$ & $(0.011)$ \\
\hline Egalitarianism & $0.053 * * *$ & $(0.010)$ & $0.053 * * *$ & $(0.010)$ & $0.053 * * *$ & $(0.010)$ & $0.053 * * *$ & $(0.010)$ \\
\hline Lesbian/Gay Contact & $0.114^{*}$ & $(0.060)$ & $0.114 *$ & $(0.060)$ & $0.114 *$ & $(0.060)$ & $0.114^{*}$ & $(0.060)$ \\
\hline Transgender Contact & $0.222 * *$ & $(0.076)$ & $0.223 * *$ & $(0.077)$ & $0.223 * *$ & $(0.077)$ & $0.221 * *$ & $(0.077)$ \\
\hline Education & 0.005 & $(0.017)$ & 0.004 & $(0.017)$ & 0.005 & $(0.017)$ & 0.005 & $(0.017)$ \\
\hline Race (white) & 0.040 & $(0.060)$ & 0.041 & $(0.060)$ & 0.041 & $(0.060)$ & 0.039 & $(0.060)$ \\
\hline Religiosity & -0.007 & $(0.018)$ & -0.008 & $(0.018)$ & -0.007 & $(0.018)$ & 0.005 & $(0.023)$ \\
\hline Evangelical & $-0.279 * * *$ & $(0.067)$ & $-0.277 * * *$ & $(0.067)$ & $-0.279 * * *$ & $(0.067)$ & $-0.281 * * *$ & $(0.067)$ \\
\hline LGBT & 0.090 & $(0.077)$ & 0.092 & $(0.077)$ & 0.090 & $(0.077)$ & 0.090 & $(0.077)$ \\
\hline Age (logged) & $-0.139 *$ & $(0.068)$ & $-0.141 *$ & $(0.069)$ & $-0.140 *$ & $(0.069)$ & $-0.142 *$ & $(0.069)$ \\
\hline Party Identification $(\mathrm{D} \rightarrow \mathrm{R})$ & $-0.025 \#$ & $(0.017)$ & $-0.025 \#$ & $(0.017)$ & $-0.025 \#$ & $(0.017)$ & $-0.025 \#$ & $(0.017)$ \\
\hline Ideology (Lib. $\rightarrow$ Cons.) & -0.009 & $(0.023)$ & -0.009 & $(0.023)$ & -0.009 & $(0.023)$ & -0.009 & $(0.023)$ \\
\hline Constant & $4.685 * * *$ & $(0.340)$ & $4.610 * * *$ & $(0.372)$ & $4.726 * * *$ & $(0.352)$ & $4.661 * * *$ & $(0.334)$ \\
\hline $\mathrm{R}^{2}$ & 0.46 & & 0.46 & & & & & \\
\hline
\end{tabular}

Notes: $\mathrm{N}=1,020$; data from GfK survey administered October 9-11, 2015

$\# p<0.1 ; * p<0.05$; ** $p<0.01$; *** $p<0.001$; directional tests where appropriate 


\section{Figures}

Figure 1. Attitudes toward Transgender Military Service, October 2015

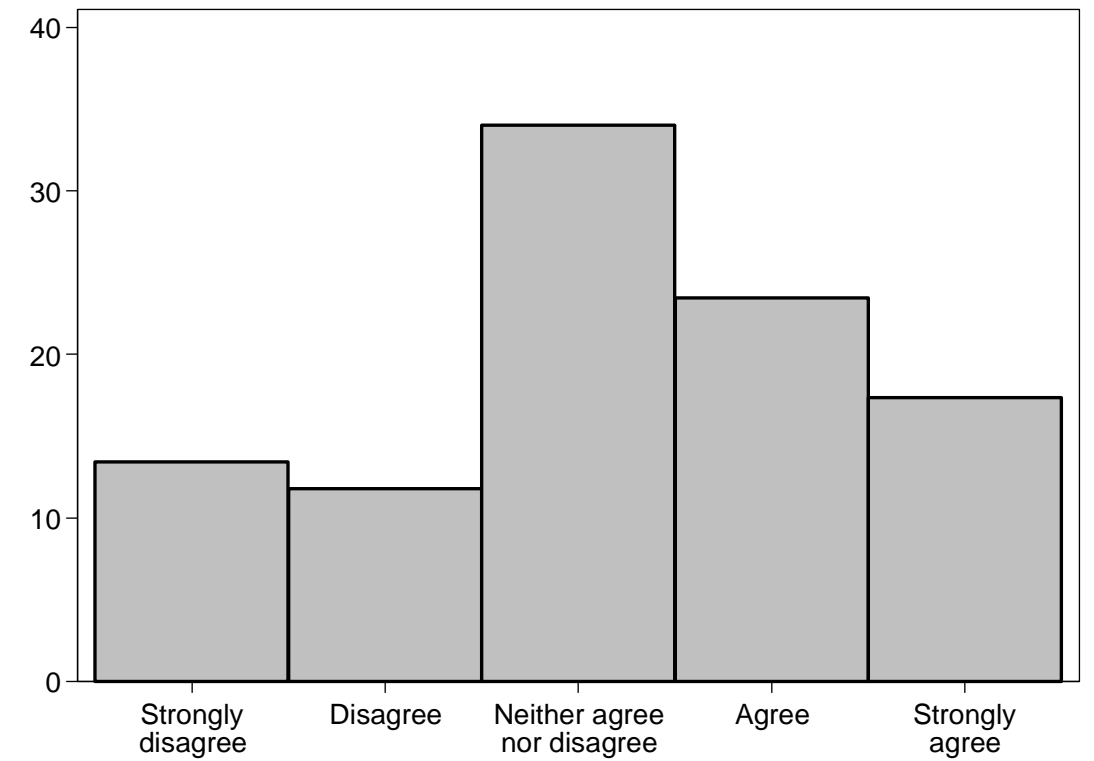

Allowing transgender people to serve openly in the military

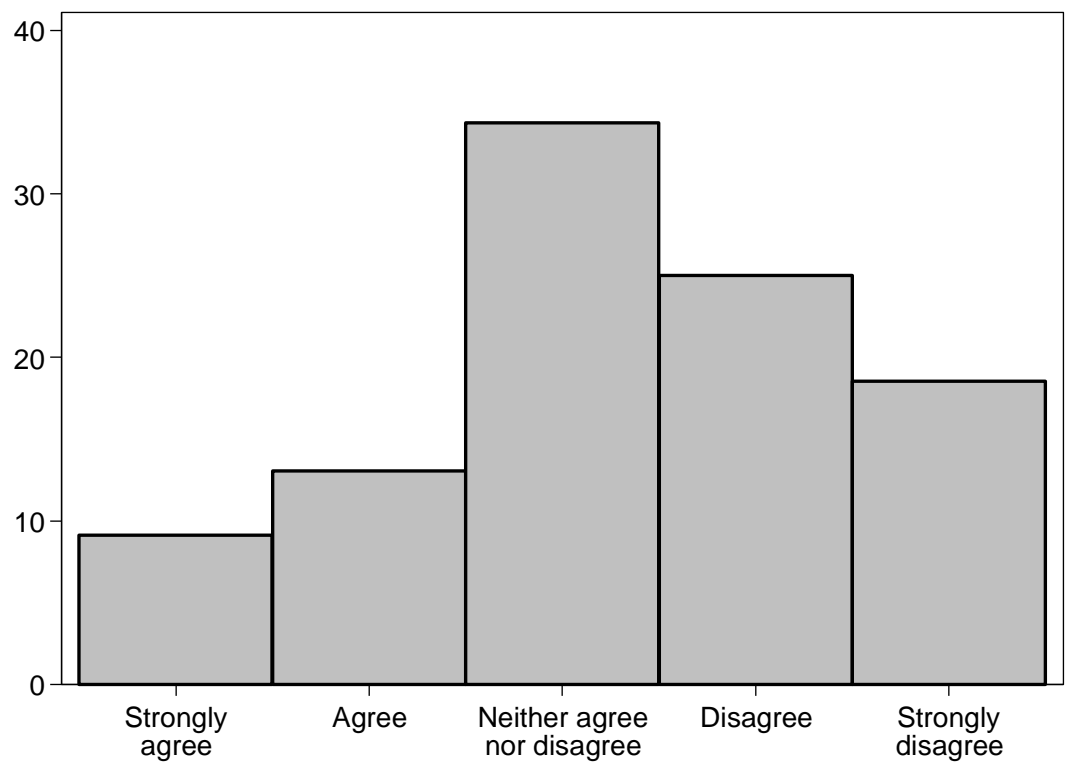

Transgender people should not be allowed to serve openly in the military. 
Figure 2. Marginal Effect of Sex across Values of Gender Identity Congruence

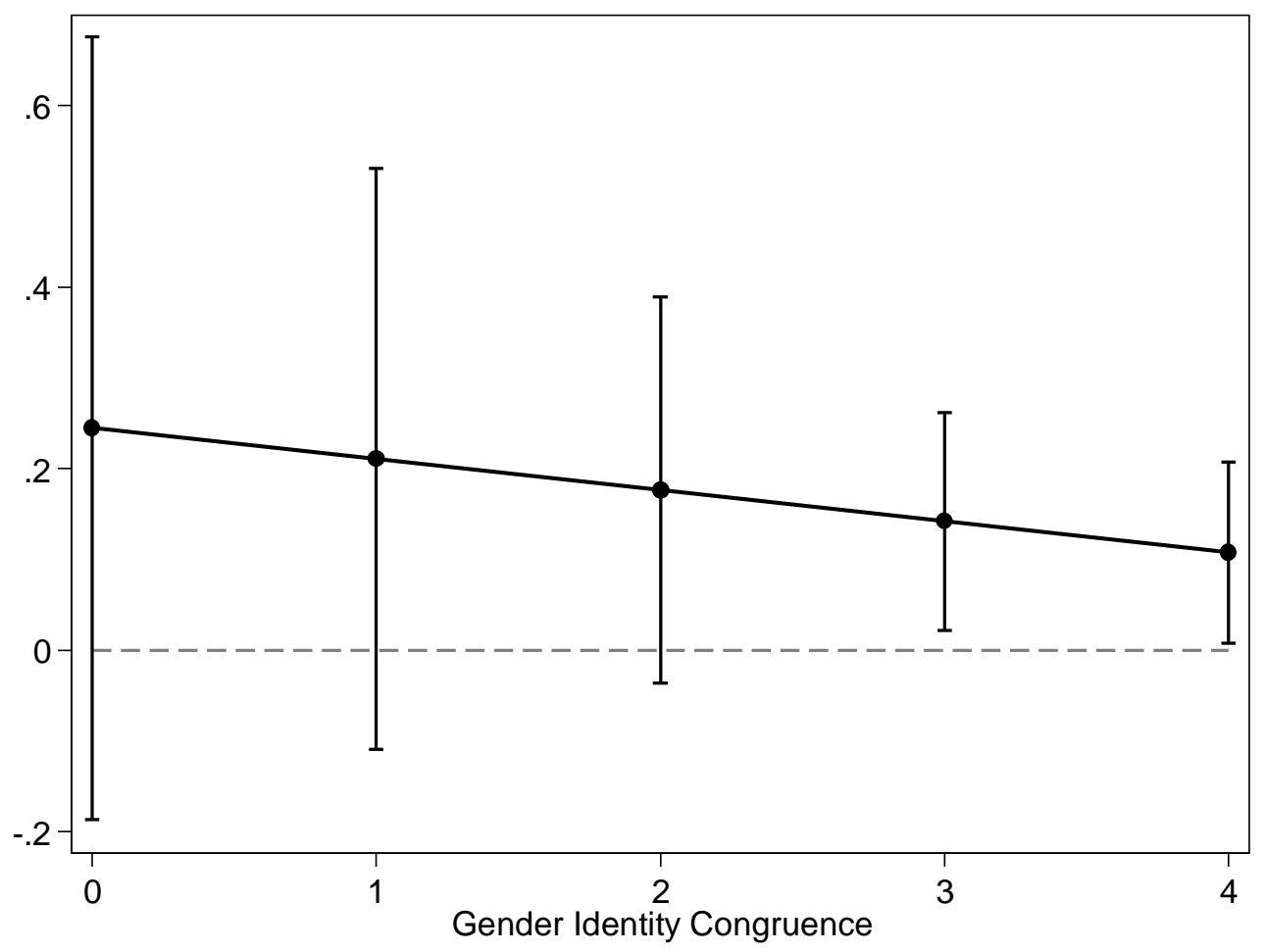

Note: Range bars represent $90 \%$ confidence intervals.

Figure 3. Marginal Effect of Sex Across Values of Gender Traditionalism

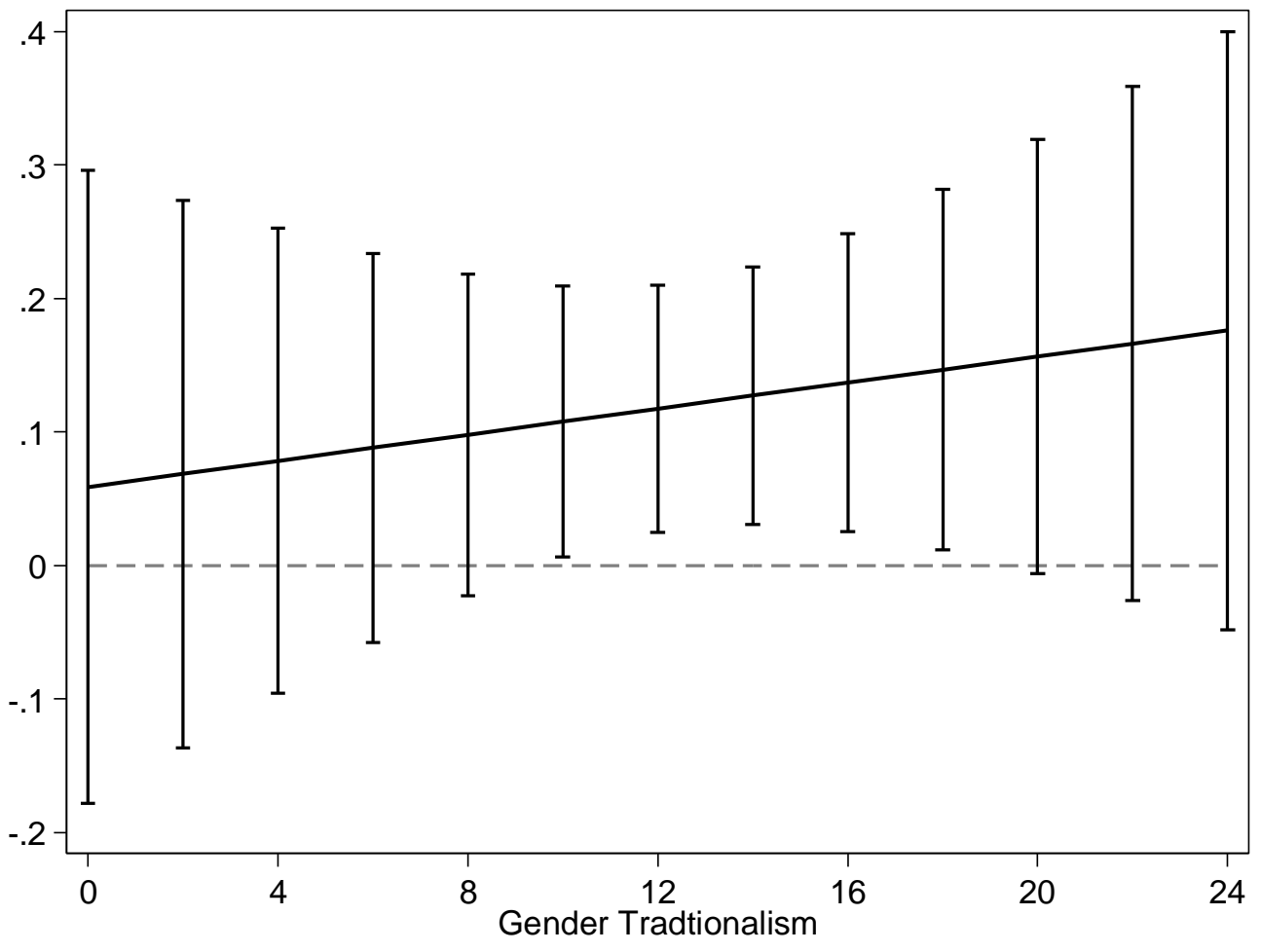

Note: Range bars represent $90 \%$ confidence intervals. 
Figure 4. Marginal Effect of Sex Across Values of Religiosity

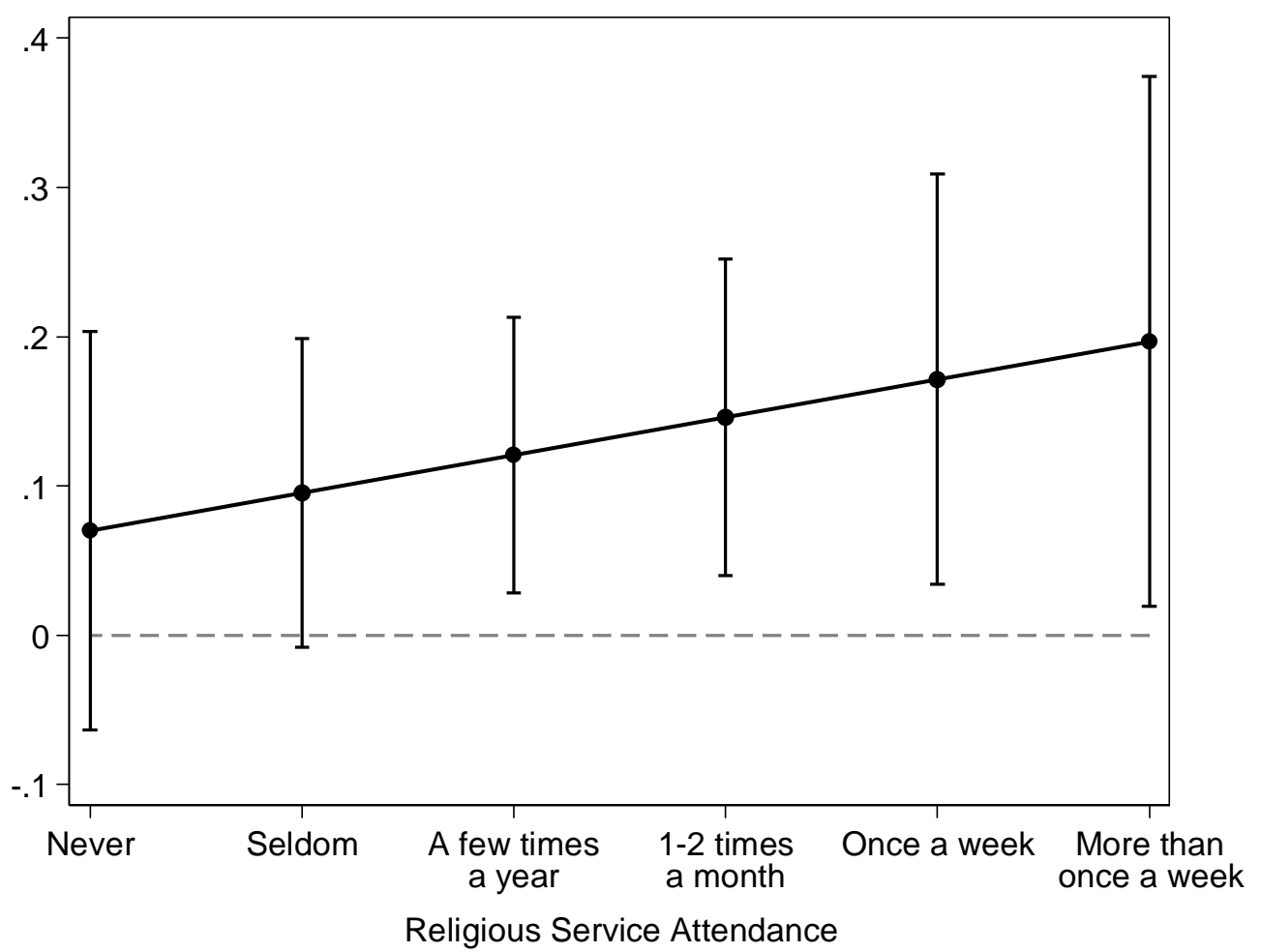

Notes: Range bars represent $90 \%$ confidence intervals. Religiosity scale reversed from model 